International Journal of STEM Education for Sustainability, Vol 2, No.1, 2022, pp. 45-52

e-ISSN 2798-5091. DOI. 10.53889/ijses.v2i1.22

\title{
STEM Clubs: The Promising Space to Foster Students' Creativity
}

\author{
Submitted 27 August 2021 Revised 4 November 2021 Accepted 27 January 2022 \\ Nguyen Thi Van Anh ${ }^{1}$, Nguyen Van Bien², Dang Van Son ${ }^{3}$, Nguyen Thi To Khuyen ${ }^{4}$ \\ ${ }^{1}$ Military University of Culture \& Arts, Hanoi, Viet Nam \\ ${ }^{2}$ Hanoi National University of Education, Hanoi, Viet Nam \\ ${ }^{3} S^{3}$ academy for creation, Hanoi, Viet Nam \\ ${ }^{4}$ Graduate Institute of Science Education, National Taiwan Normal University, Taipei, Taiwan \\ Corresponding email: *biennv@hnue.edu.vn
}

\begin{abstract}
The rapid developments of Science and Technology call for individuals to have strong academic knowledge and creativity. Research shows that students acquire creativity after either curricular or extracurricular activities in subject matters. However, there is not much research examining students' creativity through integrative learning activities, such as STEM activities. In this current study, we examine the potential of STEM clubs in terms of fostering students' creativity. We used the survey method to assess students' creativity in engineering design. We collected the data from 244 Vietnamese students, including members and non-members in STEM clubs. The quantitative analysis was performed to examine the differences between members' creativity and non-members' creativity. The results show that STEM club members have significantly more creativity than non-members. The results also show that STEM club members have significantly more creativity than non-members. Based on the results, STEM clubs demonstrate a significant impact on students' creativity. Consequently, STEM clubs should be implemented in high school to enhance students' creativity.
\end{abstract}

Keyword: Creativity, Engineering design, Assessment, STEM activities, STEM clubs

\section{INTRODUCTION}

The rapid development of science and technology requires human resources with strong academic knowledge and creativity. Creativity is one of the keywords describing human resources to meet future jobs (Bøe, Henriksen, Lyons, \& Schreiner, 2011). Essential achievements in history were discovered or invented by people through creativity, not only by intelligence. The goal of education is to train human resources and prepare for the future, so promoting creativity in general education is a priority (Romeike, 2007).

One of the activities to promote creativity is integration, such as integrating math and science, through STEM and STEAM. Creativity can be best developed through integrated activities instead of teaching subject separately (Kim, Roh, \& Cho, 2016). One of the twelve ways to foster creativity proposed by $\mathrm{Wu}$ is to apply an interdisciplinary perspective (Wu, 2002). Experienced activities in integrated education programs help foster student creativity (Lou, Chou, Shih, \& Chung, 2017). STEAM education is an educational model that allows for inspiring interest, curiosity, explains phenomena through creative thinking and action (Lee, Baek, \& Lee, 2013). For example, in an STEM interdisciplinary approach, Science aims to understand the world and define the objective laws of nature; Math helps to describe and 
analyze problems in situations, while technological achievements are based on the application of natural laws (science) and creativity in engineering design (Huang, Tsai, Diez, \& Lou, 2014).

\section{Engineering Design in Integrated STEM Education}

Integrated STEM education combines some or all of the four disciplines - science, technology, engineering, and math - into a lesson, based on the relationship between subjects and practical issues. The integrated STEM program may contain a significant academic goal of one subject, but the context may be related to other STEM subjects (Moore et al., 2014). According to Kelley, STEM integrated education is an approach to teaching the content of two or more STEM fields in a defined context to enhance student learning (Kelley \& Knowles, 2016).

In STEM lessons, students are often guided by the engineering design process, from problem identification or technical challenge design, and creating and developing solutions. The trial-and-error (loop) process is also a part of the lesson to create solutions (Anne Jolly, n.d.). The engineering design process provides students with a systematic approach to solving problems in STEM fields (Brown, 2012). Engineering design offers an opportunity to guide and make a connection between STEM industries, which is the key to an integrated topic design (Frykholm \& Glasson, 2005) (Barnett \& Hodson, 2001). The engineering design approach creates an opportunity to apply scientific knowledge and provides a practical context to apply mathematical knowledge in the design process (Kelley \& Knowles, 2016). Moreover, this approach also allows students to build new scientific and mathematical understanding through design analysis and scientific research (Thibaut et al., 2018). In engineering practice, design and scientific research are intertwined by applying scientific knowledge and design behaviors.

\section{Creativity in Engineering Design}

Creativity is the ability to create unique products that match the context and overcome the limitations of the task (Sternberg \& Lubart, 1995). Creativity should be unique, useful or suitable in practical situations and must be put into practice (Martindale, 1989). Creative thinking refers to the way people approach current problems and offer solutions (Amabile, 1998). Creativity is the creation of new and unique ideas (Rubenstein, 2000). Problem-finding can increase creative products in engineering and need more research in the future (Nickerson, 1999). Problem-finding is part of a routine job for a design engineer who needs to think and solve unknown problems (Ferguson, 1992). Creativity is determined when the technical solutions proposed by students are newly combined with suitability, value, or usefulness (Fodor $\&$ Carver, 2000). Creativity includes originality (novelty) and usefulness (ability to apply in practice) (Shah, Smith, \& Vargas-Hernandez, 2003) (Thompson \& Lordan, 1999). 
Engineers solve aesthetic problems like artists; they also prevent potential issues and solve problems based on limitations and specifications. Moreover, another aspect of technical innovation is functional creation, a type of innovation related to products such as business information systems, a service process, a technique, or a method (manufacturing process, control process, logistics) (Cropley \& Cropley, 2005).

In addition to ensuring novelty and usefulness, technical creativity is limited by meeting technical limitations (specific context, environment, economy, system integration, communication). Specifications, operating principles, and problem-solving are also an important parts of the process. Therefore, teaching STEM can promote creativity in the engineering design of students. However, there have not been many studies on students' creativity assessment through STEM activities.

In this study, we assess the potential of STEM clubs to promote creativity by conducting creative tests in the engineering design of students participating in STEM clubs. We focus on the following two research questions:

1. What are the differences between STEM club members' creativity and non-members' creativity?

2. How do gender factors, regions, school characteristics, subject interests affect high school student's creativity engineering design?

\section{METHOD}

Two hundred forty-four students were administered from 13 high schools in the North (11 schools), and the Central (5 schools) of Vietnam, consisting of 137 students (108 males and 29 females) participated STEM Club, and 107 students (72 males, 34 females) did not participate in STEM club. STEM clubs are held after class (extra-curricular): 1-2 sessions per week, about 90 minutes per session. Students are required to perform tasks, designing and manufacturing a product, solving practical problems, such as environmental pollution, water pollution, and "dirty" food. All students must complete a demographic questionnaire and creative engineering design assessment (CEDA). Data that does not meet the following requirements will be rejected:

The students do not make any CEDA requirements

$>$ The students did not complete all the questions on the demographic questionnaire

The students do not actually concentrate on the assignment.

We obtained complete data from 131 students, including 83 students (68 males or $81.9 \%$; 15 females or $18.1 \%$ ) who participated in STEM Club, and 48 students (35 males respectively 
72, 9\%, 13 females, respectively, 27.1\%) did not participate in STEM club. The quantitative method was used for data analysis via SPSS 25 for Windows.

\section{Instruments}

\section{Creativity Engineering Design Assessment (CEDA)}

Although CEDA is designed to assess creativity in the engineering design of undergraduate students, educators can use CEDA to evaluate creativity in the engineering design of high school students (Charyton \& Merrill, 2009). CEDA evaluates both divergent and convergent thinking. CEDA measures both divergent and convergent thinking. CEDA measure based on the properties of creativity: originality (new ideas), fluency (number of ideas created), flexibility (number of different types / groups of ideas), usefulness (application).

The CEDA includes three design requirements. For each request, students need to complete five parts: sketch, description (what is your design?), description of the materials, additional problems solved, and users (persons that could use design) for each design. Students use three-dimensional figures to generate two original designs that will accomplish the general goal written below-set figures on an A4 page. The total time is 30 minutes for 3 pages or about 10 minutes per page. Student creativity is assessed based on the sum of the component scores: originality (0-10), fluency (counting the number of ideas/responses), flexibility (counting the number of category types), and usefulness (0-4) for each design request.

CEDA was translated into Vietnamese and tested on 20 high school students to standardize the test. Then, it was used as a pre-test and post-test to assess students when participating in a STEM club. Two design professionals were selected to score subsets of the CEDA's; each judge evaluated the CEDA's separately. Correlations between the two judges were strong $(r=0.904 * *)$; therefore, the average score between the two judges was used for analysis.

\section{Demographic questionnaire}

Students filled in information about gender, age, region and answered questions about interest in STEM subjects such as: 'what is your favorite subject?' or 'Which subjects are useful in your life?' For each question, we divided it into three groups: favorite, useful, and combination of favorite and useful.

For favorite subject, students were divided into 3 groups: group F_1 includes keen students on fewer STEM subjects than 2; group F_2 includes students who were keen from 3 to 4 STEM subjects; group F_3 includes students who were keen from 5 to 6 subjects STEM. 
For useful subjects, students are divided into 3 groups: U_1 group consists of students who felt fewer useful subjects than 2; group U_2 includes students who felt from 3-4 useful STEM subjects; group F_3 includes students who felt from 5 to 6 STEM subjects are useful.

In addition, we also classify students who both keen on and felt useful STEM subjects into 3 groups: FU_1 group of students who keen on and felt useful fewer STEM subjects than 2; group FU_2 includes students who keen on and felt useful from 3 to 4 STEM subjects; FU_3 group includes students who keen on and felt useful from 5 to 6 STEM subjects.

\section{RESULTS AND DISCUSSION}

The results of the t-test showed significant creativity engineering design differences between the students who joined the club and the students who did not join the club ( $p=0.008$ $<0.05)$. The scores of students participating in the club $(63,235)$ are higher than those of nonmember $(53,563)$. No significant difference were found as gender $(\mathrm{p}=0.8>0.05)$, region $(\mathrm{p}=$ $0.542>0.05$ ) or between students of specialized schools and students of non-specialized schools $(\mathrm{p}=0.911>0.05)$.

For students who participated in STEM clubs, 32.5\% of students were keen on fewer STEM subjects than 2 (group F_1), $48.2 \%$ of students keen on from 3 to 4 STEM subjects (group F_2) and $19.3 \%$ of students keen on from 5 to 6 subjects STEM (group F_3) (see table 1). An ANOVA was used to test for differences in three groups. No significant differences were found for the groups. However, post host test results show a significant difference between the $\mathrm{F} \_2$ group and $\mathrm{F} \_3$ group $(\mathrm{p}=0.033)$. The mean of group $\mathrm{F} \_3(72,281)$ is $11.6812 *$ higher than group F_2 $(60,600)$.

From the data, the usefulness of STEM subjects, $22.9 \%$ of students felt fewer useful subjects than 2 (group F_1), 48.2\% of students felt from 3-4 useful STEM subjects (group F_2) and $28.9 \%$ of students felt from 5 to 6 STEM subjects are useful (group F_3) (see Table 1). There were no significant differences between the 3 groups with ANOVA $(\mathrm{p}=0.313)$.

Combining both the engagement and the usefulness of STEM subjects, only $10.9 \%$ of students were keen on and felt useful from 5 to 6 STEM subjects (FU_3 group); $36.1 \%$ of students were keen on and felt useful from 3 to 4 STEM subjects (FU_2 group) and 53\% of students were keen on and felt useful fewer STEM subjects than 2 (FU_1 group) (see table 1). ANOVA analysis results show that there are differences between the 3 groups $(p=0.016)$. Specifically, the mean of FU_3 $(79,167)$ is 15.7833 * significant higher than FU_2 $(63,383)$ (p $=0.022<0.05)$. The mean of the FU_3 group $(79,167)$ is $19.2917 *$ significant higher than the FU_1 group $(63,383)(\mathrm{p}=0.004<0.05)$. 
International Journal of STEM Education for Sustainability, Vol 2, No.1, 2022, pp. 45-52

e-ISSN 2798-5091. DOI. 10.53889/ijses.v2i1.22

Table 1. Group ratio of interest and usefulness of subjects

\begin{tabular}{lcccc}
\hline & $\begin{array}{c}\text { Favorite }(\mathrm{F}) \\
(\%)\end{array}$ & $\begin{array}{c}\text { Useful }(\mathrm{U}) \\
(\%)\end{array}$ & $\begin{array}{c}\text { Favorite \& useful (FU) } \\
(\%)\end{array}$ \\
\hline Group & 1 & 32.5 & 22.9 & 53.0 \\
& 2 & 48.2 & 48.2 & 36.1 \\
& 3 & 19.3 & 28.9 & 10.8 \\
\hline
\end{tabular}

Our first research question is concerned about the creativity in engineering design of members and non-members in STEM clubs. The results of the t-test show that students participating in STEM clubs are more creative than a non-member. The authors speculate that students are often required to design and manufacture a product when joining STEM clubs. Through these activities, students develop engineering thinking and creativity in engineering design.

Secondly, similarities were found in creative engineering design between male and female members in STEM clubs, like the past study by Charryton (Charyton, Jagacinski, Merrill, Clifton, \& Dedios, 2011). This may be because female students participating in STEM clubs are students who like design activities and have strong Design Thinking. Moreover, there were no significant differences between creativity design engineers of students from different regions and school groups (specialized or non-specialized schools).

Our finding also indicates that students who love most STEM subjects are more creative in design engineering than others. Students who have both the engagement and usefulness of STEM subjects are more creative in design engineering than others, so encouraging students' interest in STEM subjects and career direction is highly important.

Limitations of this study include fewer female students than male students in STEM clubs. Females are approximately $18 \%$ of the overall member of STEM clubs. Therefore, more girls need greater encouragement to join STEM clubs.

\section{CONCLUSION}

It can be seen that STEM integrated activities promote students' creativity in engineering design. More opportunities are needed for students to participate in STEM activities. Students can develop creativity in engineering design through these activities, thereby contributing to inventions for society.

Moreover, students are more interested in STEM subjects the higher their creativity in engineering design. Encouraging students' interest in STEM subjects and career direction is significant for high school education. Future research is needed with more samples and a balance between the number of male and female students. 


\section{REFERENCES}

Amabile, T. M. (1998). How to kill creativity (Vol. 87). Harvard Business School Publishing Boston, MA.

Anne Jolly. (n.d.). Six Characteristics of a Great STEM Lesson. Retrieved May 14, 2019, from https://www.edweek.org/tm/articles/2014/06/17/ctq_jolly_stem.html

Barnett, J., \& Hodson, D. (2001). Pedagogical context knowledge: Toward a fuller understanding of what good science teachers know. Science Education, 85(4), 426-453.

Bøe, M. V., Henriksen, E. K., Lyons, T., \& Schreiner, C. (2011). Participation in science and technology: young people's achievement- related choices in late- modern societies. Studies in Science Education, 47(1), 37-72.

Brown, J. (2012). The current status of STEM education research. Journal of STEM Education, 13(5), 7-12. Retrieved from http://search.proquest.com/docview/1266493670?accountid=16369

Charyton, C., Jagacinski, R. J., Merrill, J. A., Clifton, W., \& Dedios, S. (2011). Assessing creativity specific to engineering with the revised Creative Engineering Design Assessment. Journal of Engineering Education. https://doi.org/10.1002/j.21689830.2011.tb00036.x

Cropley, D., \& Cropley, A. (2005). Engineering creativity: A systems concept of functional creativity. In Creativity across domains (pp. 187-204). Psychology Press.

Ferguson, E. S. (1992). Engineering and the Mind's Eye. MIT press.

Fodor, E. M., \& Carver, R. A. (2000). Achievement and power motives, performance feedback, and creativity. Journal of Research in Personality, 34(4), 380-396.

Frykholm, J., \& Glasson, G. (2005). Connecting science and mathematics instruction: Pedagogical context knowledge for teachers. School Science and Mathematics, 105(3), $127-141$.

Huang, Y.-T., Tsai, C.-C., Diez, C. R., \& Lou, S.-J. (2014). The application of game-based elearning for the learning of linear equations in two unknowns. Journal of Computers and Applied Science Education, 1(1), 1-25.

Kelley, T. R., \& Knowles, J. G. (2016). A conceptual framework for integrated STEM education. International Journal of STEM Education, 3(1), 237. https://doi.org/10.1186/s40594-016-0046-z M4 - Citavi

Kim, M. K., Roh, I. S., \& Cho, M. K. (2016). Creativity of gifted students in an integrated mathscience instruction. Thinking Skills and Creativity, 19, 38-48. https://doi.org/10.1016/j.tsc.2015.07.004

Lee, S., Baek, J., \& Lee, J. (2013). The Development and the Effects of Educational Program applied on STEAM for the Mathematical Prodigy. Education of Primary School Mathematics, 16(1), 35-55. 
Lou, S. J., Chou, Y. C., Shih, R. C., \& Chung, C. C. (2017). A study of creativity in CaC 2 steamship-derived STEM project-based learning. Eurasia Journal of Mathematics, Science and Technology Education, 13(6), 2387-2404. https://doi.org/10.12973/EURASIA.2017.01231A

Martindale, C. (1989). Personality, situation, and creativity. In Handbook of creativity (pp. 211232). Springer.

Moore, T. J., Stohlmann, M. S., Wang, H. H., Tank, K. M., Glancy, A. W., \& Roehrig, G. H. (2014). Implementation and integration of engineering in K-12 STEM education. In Engineering in pre-college settings: Synthesizing research, policy, and practices. Purdue University Press.

Nickerson, R. S. (1999). 20 Enhancing Creativity. Handbook of Creativity, 392.

Romeike, R. (2007). Applying creativity in CS high school education: criteria, teaching example and evaluation. In Proceedings of the Seventh Baltic Sea Conference on Computing Education Research-Volume 88 (pp. 87-96). Australian Computer Society, Inc.

Rubenstein, D. J. (2000). Stimulating children's creativity and curiosity: Does content and medium matter? The Journal of Creative Behavior, 34(1), 1-17.

Shah, J. J., Smith, S. M., \& Vargas-Hernandez, N. (2003). Metrics for measuring ideation effectiveness. Design Studies, 24(2), 111-134.

Sternberg, R. J., \& Lubart, T. I. (1995). Defying the crowd: Cultivating creativity in a culture of conformity. Free Press.

Thibaut, L., Ceuppens, S., De Loof, H., De Meester, J., Goovaerts, L., Struyf, A., ... Depaepe, F. (2018). Integrated STEM Education: A Systematic Review of Instructional Practices in Secondary Education. European Journal of STEM Education, 3(1), 1-12. https://doi.org/10.20897/ejsteme/85525

Thompson, G., \& Lordan, M. (1999). A review of creativity principles applied to engineering design. Proceedings of the Institution of Mechanical Engineers, Part E: Journal of Process Mechanical Engineering, 213(1), 17-31.

Wu, J. J. (2002). Enticing the crouching tiger and awakening the hidden dragon: Recognizing and nurturing creativity in Chinese students. Research in Applied Psychology, 15, 17-42. 